\title{
Study of Infertile Couples Attending a Teaching Hospital in Eastern Nepal
}

Shanti Subedi, ${ }^{1}$ Sabina Lamichhane, ${ }^{1}$ Manisha Chhetry ${ }^{1}$

'Department of Obstetrics and Gynecology, Nobel Medical College, Biratnagar, Nepal.

\section{ABSTRACT}

Introduction: Infertility is a global health issue and a socially destabilizing condition for couples with several stigmas including medical, social, psychological burdens and a marital disharmony. The aim was to study the incidence of infertility in couples attending outdoor of Nobel Medical College and to know the contributing factors among the infertile couples.

Methods: A prospective cross-sectional study was carried out in the outpatient department of a teaching hospital July 2015 - June 2016, where the incidence of infertility and the contributing factors for the same were evaluated.

Results: The incidence of infertility in this study was $5.45 \%$ and it was dominated by secondary infertility. The most important cause was male factor in $37.39 \%$. Majority of male factor abnormality was due to exposure to heat as these male work abroad in Arabian Countries.

Conclusions: The study shows a dominance of secondary infertility and male factor being a major contributor. The most common semen abnormality was oligospermia.

Keywords: infertility; incidence; oligospermia; semen.

\section{INTRODUCTION}

Infertility is a global health issue and one of the commonest causes for marital disharmony. Although the statistics for infertility vary greatly from country to country and are only an estimate due to the sensitive nature of the condition. Although the estimates vary, approximately $15 \%$ of couples attempting their first pregnancy meet with failure. A global review of infertility from the World Fertility Survey and others estimated similar rates of infertility in other settings in South Asia, such as $4 \%$ in Bangladesh, $6 \%$ in Nepal, $5 \%$ in Pakistan and $4 \%$ in Sri Lanka. ${ }^{1}$

One estimate of overall primary and secondary infertility in South Asia, on the basis of women at the end of their reproductive lives in the age group 45-49 years, suggests an infertility rate of approximately 10\%: $8 \%$ in India, $10 \%$ in Pakistan, $11 \%$ in Sri Lanka, $12 \%$ in Nepal and $15 \%$ in Bangladesh. ${ }^{2}$ Infertility is defined as failure to achieve pregnancy after a year of unprotected intercourse. $^{3}$ This is further classified as primary if the couples fail to achieve previous pregnancy and secondary if a prior pregnancy, although not necessarily a live birth, has occurred. ${ }^{3}$

The main causes of infertility has been categorized as male factor in $25-40 \%$, female factor in $40-55 \%$, which can be due to ovulatory dysfunction, tubal or peritoneal factors, Uterine and cervical causes and unexplained in $10 \% .^{3}$ The aim of the study was to know the incidence of infertility and to identify the factors responsible for the same.

Correspondence: Dr. Shanti Subedi, Department of Obstetrics and Gynecology, Nobel Medical College, Biratnagar, Nepal. Email: subedi007@gmail.com, Phone: +977-9842021806. 


\section{METHODS}

A prospective cross-sectional study was conducted in the department of Obstetrics and Gynecology, Nobel Medical College Teaching Hospital, Biratnagar from July 2015-June 2016. Ethical clearance was taken from the hospital IRC. All the patients with the complain of inability to conceive for a period of at least one year were recruited. A total of 2200 patients were seen in the outdoor during the study period and the study sample included a total of 120 couples with the infertility problem. The detail history of the couples and physical examination of the female partner was done and for male partner, examination was done by urologist if at all semen analysis was found to be abnormal. All the patients had undergone semen analysis after three days of abstinence, abdominal ultrasound, hysterosalpinography on day 6-day 11 and hormonal assessment included thyroid function test and serum prolactin as a routine. Results of semen analysis was interpreted according to WHO criteria.

Following reference values were taken as normal for thyroid function test-
1. Serum T3
$0.77-1.98 \mathrm{ng} / \mathrm{ml}$
2. Serum T4
$6.09-12.23 \mathrm{ug} / \mathrm{ml}$
3. Serum TSH
$0.34-5.12 \mathrm{ulU} / \mathrm{ml}$

For serum prolactin, $5-25 \mathrm{ng} / \mathrm{ml}$ was considered normal.

Diagnostic laparoscopy with chromopertubation was done if HSG was abnormal and if adnexal mass was noted on clinical examination and on ultrasound. Out of 120 , five patients were lost to follow up.

After obtaining consent, the case notes were prepared and relevant clinical findings and results of investigations were documented using a structured questionnaire and finally data were extracted from the same and analyzed using SPSS version 11.

\section{RESULTS}

The total number of patients attending Gynecology outdoor during the study period was 2200. Out of these, 120 patients were recruited with a diagnosis of infertility and 5 of them were lost to follow up.

The incidence of infertility was $120(5.45 \%)$ and of these 65 (56.5\%) had secondary and 37 (43.47\%) had primary subfertility. Most of the patients seek medical advice earlier in less than 5 years (Table 1 ).

Among men with azoospermia, 5 of them had history of exposure with heat as they were working in Arabian countries, 1 had undergone right orchidectomy, 1 had hydrocele and the other one no identifiable cause was found (Table 2). Among men with oligospermia, 15 of them had history of exposure to heat (works in Arabian countries and driver), two had hydrocele and one had history of trauma to the testis. In asthenospermia cases, 2 were chronic alcoholic and 2 had history of repair of hernia. Men who consumes alcohol more than once a week were considered alcoholics and none of the male partner were found to be a chronic smokers (>10 cigarettes/day).

Regarding the possible causes, male factor accounted for $43(37.39 \%)$ and for female factors, tubal cause accounted for $17(14.78 \%)$, hypothyroidism in 10 $(8.69 \%)$ and hyperprolactinaemia in $3(2.60 \%)$, both the factors was accountable in $25(21.73 \%)$ and 17 $(14.78 \%)$ were unexplained infertility (Table 3,4$)$.

One of the patients with bilateral tubal block had past history of TB endometrium with ATT taken for complete 9 months. In other patients no such specific history for the tubal block could be elicited.

\begin{tabular}{|l|l|}
\hline \multicolumn{2}{|l|}{ Table 1. Socio-Demographic Characteristics. } \\
\hline Variables & $\mathbf{n = 1 1 5}(\%)$ \\
\hline $\begin{array}{l}\text { 1. Age (years) } \\
<20\end{array}$ & $15(13.04 \%)$ \\
$20-29$ & $80(69.56 \%)$ \\
$30-39$ & $12(10.43 \%)$ \\
$>40$ & $8(6.95 \%)$ \\
\hline 2. Duration of infertility (years) & \\
$<1-5$ & $70(60.86 \%)$ \\
$6-10$ & $20(17.39 \%)$ \\
$11-15$ & $13(11.30 \%)$ \\
$16-20$ & $7(6.08 \%)$ \\
$>20$ & $5(4.34 \%)$ \\
\hline 3.Type of infertility & $65(56.52 \%)$ \\
Primary & $50(43.47 \%)$ \\
\hline
\end{tabular}

Table 2. Semen Analysis $(\mathbf{n}=115)$.

\begin{tabular}{|ll|}
\hline Normal & $\mathrm{n}=72(62.6 \%)$ \\
Azoospermia & $8(6.95 \%)$ \\
Oligospermia & $25(21.73 \%)$ \\
Asthenospermia & $10(8.69 \%)$ \\
\hline
\end{tabular}


Table 3. Investigation result of female partner.

Variables $n=115(\%)$

1. Ultrasound -

Adnexal pathology

Polycystic ovaries

$6(5.21 \%)$

Uterine myoma

$25(21.73 \%)$

Fluid in Pouch of Douglas

$2(1.73 \%)$

$20(17.39 \%)$

2. Hysterosalpingography

$\begin{array}{ll}\text { Bilateral tubal block } & 9(7.82 \%) \\ \text { Right tubal block } & 4(3.47 \%) \\ \text { Left tubal block } & 1(0.86 \%) \\ \text { Hydrosalpinx } & 3(2.60 \%)\end{array}$

Table 4. Hormonal parameters of female partner.

\begin{tabular}{|ll|}
\hline Variables & $\mathbf{n = 1 1 5}(\%)$ \\
Thyroid function & Hypothyroid -10 \\
test- & $(8.69 \%)$ \\
& Hyperprolactinaemia \\
Serum Prolactin & $-3(2.60 \%)$ \\
\hline
\end{tabular}

\section{DISCUSSION}

Infertility is considered a stigma and a major public health problem in many countries. ${ }^{4}$ In spite of the increased infertility services rendered these days, its prevalence still remains around $10-15 \% .{ }^{5}$ Global estimates in 2007 suggest that nearly 72.4 million couples experience fertility problem. ${ }^{6}$ However, the exact number of prevalence is hard to estimate because of the appropriate survey method, criteria to establish the diagnosis of infertility, outcome measured that is pregnancy or live birth rate.

The incidence of infertility in our study was $5.45 \%$ and it varies, it was reported to be $4 \%$ in Ilorin, $78.1 \%$ reported in Oshogbo. ${ }^{8}$ this low incidence in our study may be due to early marriage as compared to western culture. Marriage is early and universal, and it is viewed as a disgrace for a couple, particularly for the wife, not to have children. Traditionally, Nepalese society has favored high fertility. Children are considered a symbol of both social and economic well being. High fertility include early and universal marriage as well as desire for sons, for both religious and economic purpose. ${ }^{9}$

The predominance of secondary infertility (56.52\%) in this study is similar to the studies done in Africa, ${ }^{10-12}$ where as in Western population primary infertility accounting for $61-71 \%$ of cases. ${ }^{13}$ This could be due to tradition of late marriage. Another study done in Mongolia showed that $43.7 \%$ of women had secondary infertility. ${ }^{14}$

Most of the patients in this study $(60.86 \%)$ seek medical advice earlier which is contrast to the study done by Panti AA, where $53 \%$ of patients present after 5 years. ${ }^{15}$ This delay may be due to poor knowledge of infertility, unavailable or inaccessibility of appropriate services, prior unsuccessful medical interventions and previous visit to traditional healers.

This study shows a greater contribution of male factor $(37.39 \%)$ as compared female factor $(26.07 \%)$. In respect of determinants of female causes this study found that tubal factor in (14.78\%), Hypothyroidism in $(8.69 \%)$ and hyperprolactinaemia in $(2.6 \%)$. This is contrast to the study done by Panti $A A^{15}$ where female contribution for infertility was more $(42.9 \%)$ as in other studies in Nigeria. ${ }^{7,12}$ This high incidence of male factor in the study may be due to their occupation as most of them working abroad in Arabian countries. This is due to heat affecting spermatogenesis.

Among male factor, $6.95 \%$ had Azoospermia, Oligospermia in $21.73 \%$ and Asthenospermia in $8.69 \%$ in this study where as in the study done by Pant PR ${ }^{16}$, (38.9\%) had azospermia, (46.82\%) were oligospermic and $(14.28 \%)$ had asthenospermia. None of the patients in the study declined for semen analysis. The limitation of this study; sample size not adequate, lost to follow up, non-compliance with investigation.

\section{CONCLUSIONS}

Infertility is a global health issue that requires appropriate diagnosis and determinants. The incidence of infertility in the study was $5.45 \%$ and it was dominated by secondary infertility. Male factor being the most common contributing factor and exposure to heat is the main cause for it. We should focus from the grass root level by improving the literacy rate thereby uplifting the economy of the country, thus none of them have to work abroad.

\section{ACKNOWLEDGEMENTS}

I am very grateful to the infertile couples who were enrolled in this study and the supporting staffs in the clinic. 


\section{REFERENCES}

1. Vaessen M. Childlessness and infecundity. WFS Comparative Studies, Series 31. Voorburg, The Netherlands: Cross National Summaries, 1984.

2. Farely TMM, Baisey EM. The prevalence of a etiology of infertility.Proceedings, African Population Conference. 28 November 1988; Senegal, Dakar; 1998.

3. Mira Aubuchan.Infertilty and assisted Reproductive Technology.(15thed).1133-89.

4. Bello TO. Pattern of tubal pathology in infertile women on hystero-salpingography in Ilorin, Nigeria. Annals of African Medicine 2004; 3 (2): 77-9.

5. Poonam. The role of hystero salpingography in cases of subfertility. Kathmandu University Medical Journal 2007;5(4):456-60

6. Boivin J, Bunting L, Collins JA, Nygren KG. International estimates of infertility prevalence and treatment-seeking: potential need and demand for infertility medical care. Hum Reprod 2007; 22(6):1506-12. Epub 2007/03/23.

7. Obuna JA, Ndukwe EO, Ugboma HA, Ejikeme BN, Ugboma EW. Clinical presentation of infertility in an outpatient clinic of a resource poor setting, South East Nigeria. Int J Trop Disease and Health 2012; 2:123-31.

8. Adeyemi AS, Adekanle DA, Afolabi AF. Pattern of gynaecological consultations at Ladoke Akintola University of Technology Teaching Hospital. Niger J Clin Pract 2009;12:47-50
9. Karki YB: Fertility and the value of children: A stidy of rural and urban populations in Nepal. Ph. D. thesis. 1982, London school of economics, London.

10. Okonofua FE. Infertility in Sub-Saharan Africa. In: Okonofua FE, Odunsi K, editors. Contemporary Obstetrics and Gynaecology for Developing Countries. Publishers: Women's Health and Action Research Center. Benin City: 2003. p. 128-56.

11. Ekanem IA, Ekanem AD. Endometrial pathology associated with infertility among Nigerian women. Niger Postgrad Med J 2006; 13:344-7

12. Bala MA. Alfred AM, Mohammed B. Clinical presentation of infertility in Gombe, North-Eastern Nigeria. Trop J Obstet Gynaecol 2003;20:93-6

13. Templeton A, Fraser C, Thompson B. Infertility-epidemiology and referral practice. Human Reprod1991; 6:1391-4.

14. Bayasgalan G, Naranbaat D, Tsedmaa B, Tsogmaa B, Sukhee $\mathrm{D}$, Amarjargal o et al. Clinical Patterns and major causes of infertility in Mongolia.J. Obstet. Gynaecol. Res.2004; 30(5):386-93.

15. Panti AA,Sununu YT. The profile of infertility in a teaching Hospital in North West Nigeria. Sahel Med J 2114; 17:7-11.

16. Pant PR. Abnormal Semen Parameters among male in Infertile Couples. NJOG 2013 Jan-June8 ;( 1):53-55. 